\title{
The Moral Experiences of Children Living in Poverty: A Focused Ethnography
}

\author{
Marjorie Montreuil, Olivia Saint-Laurent, and Franco A. Carnevale
}

Marjorie Montreuil is a PhD student at the Ingram School of Nursing, McGill University, working with the Views On Interdisciplinary Childhood Ethics (VOICE) team. She is a Canadian Nurses Foundation scholar, and her current work is supported by the Fonds de Recherche du Québec_-Santé (FRQS) Doctoral Training Award and the Richard and Edith Strauss Fellowship in Nursing. Email: marjorie.montreuil@mail.mcgill.ca

Olivia Saint-Laurent holds a MSc in nursing from the Ingram School of Nursing, McGill University. Her research interests are in global and public health, with a focus on examining health concerns from the perspectives of vulnerable populations.

Franco A. Carnevale's current academic appointments include (all at McGill University) full professor, Ingram School of Nursing; associate member, Faculty of Medicine (Pediatrics); adjunct professor, Counselling Psychology; affiliate member, Biomedical Ethics Unit. He is the founder and principal investigator for VOICE, a McGill-based international initiative to advance knowledge and practices relating to ethical concerns in childhood.

A focused ethnography was conducted in an after-school academic support program serving vulnerable populations in Montreal, Quebec, Canada. The aim of this study was to explore the moral experiences of children living in poverty to inform on their daily experiences and moral lives. Our results highlighted that these children, who were experiencing economic hardship and/or social isolation, faced various social barriers, such as stigmatization, family isolation, and linguistic challenges for new immigrant children. As active agents, they navigated the challenges they encountered with help from the program.

Keywords: children; poverty; experience; ethnography
Article 12 of the United Nations Convention on the Rights of the Child (1989) stipulates that children have a right to express their views in all matters that affect them, and that their views should be "given due weight." In different fields, such as law, health, and social sciences, children are increasingly recognized as having a double identity: They are defined as vulnerable and requiring protection according to their "best interests," but they are also moral agents, which refers to "children's capacity to act deliberately, speak for oneself, and actively reflect on their social worlds, shaping their lives and the lives of others" (Montreuil \& Carnevale, 2016, p. 510). In this context, the aim of this study was to explore the moral experiences of children living in poverty to inform on their daily experiences and moral lives, which have been scarcely studied.

\section{Background}

\section{Childhood ethics}

Rooted in the wider field of childhood studies, childhood ethics is an emerging field of interdisciplinary inquiry recently developed to explore knowledge and practices that relate to children's moral experiences, with the goal of reconciling the notion that children are both moral agents and vulnerable (Carnevale, Campbell, Collin-Vézina, \& Macdonald, 2015; Hunt \& Carnevale, 2011; Wall, 2010). This work is based on a constructivist conception of ethics in which moral experience is socially defined through a person's interpretation of their own lived experiences situated on the spectrum of right-wrong, good-bad, or just-unjust (Hunt \& Carnevale, 2011). For an action or event to be considered a moral experience, it must bear significance for the person living it. Important aspects of moral experience are thus defined in everyday events, which we sought to explore in relation to children living in poverty.

\section{Childhood poverty in Canada}

Children living in poverty are considered to be a doubly vulnerable population: As minors, their decision-making capacity is 
transferred to surrogate actors, and they are more profoundly affected by the effects of poverty than adults (Carnevale et al., 2015). The material and social aspects of poverty directly affect food security, housing, living habits, and physical as well as psychological health. In cities, people living alone, single-parent families, and immigrant newcomers are considered as most vulnerable to poverty (Canadian Teachers' Federation, 2009). Very little is known about the experiences of children living in these contexts.

Multiple adverse outcomes are associated with poverty. Globally, poverty is recognized as the most important predictor of ill health (Ecob \& Davey Smith, 1999; United Nations Development Programme, 2014). Childhood poverty is associated with a plethora of adverse outcomes, from material disadvantage and poor mental/physical health to limited social participation and fear of marginalization (Chen, Cohen, \& Miller, 2010; Crossley \& Curtis, 2003; Ridge, 2011). Poverty can also lead to the impaired development of adequate personal relationships with both family members and peers (Barrera et al., 2002; Cui, Conger, Bryant, \& Elder, 2002; Morrow, 2001). Potential social deprivation puts children living in poverty at further risk for both psychological and physical ill health and at increased risk of mortality (Robinson, McIntyre, \& Officer, 2005). In 2015, it was estimated that one in five children in Canada lived in poverty, as defined by Canada's low-income cut-off measure (Fern, Freiler, Friendly, \& Tougas, 2015). This highlights that Canada mostly uses economic criteria alone to define poverty, while there is growing recognition internationally that the definition of poverty must take into account social exclusion and loss of opportunity (United Nations Development Programme, 2014). Groups vulnerable to social exclusion, such as new immigrant families, might therefore be underrepresented in these studies. Because of the adverse outcomes associated with poverty, children living in poverty are a particularly vulnerable population, and the study of their experiences would contribute to enhance our understanding of their daily lives.

\section{Exploring the moral experiences of children living in poverty}

Research looking at the everyday experiences of children living in poverty in Canada is very limited, and no study was found exploring children's moral experiences, in reference to what they consider morally meaningful in their everyday lives. This focus on moral experiences can also help advance our understanding of these children as active moral agents. One study documented the impact of poverty on children's social status, which is linked to feeling deprived, feeling excluded from peers (e.g., receiving labels such as "welfare babies"), having low self-esteem, or feeling responsible for improving their financial situation (Robinson et al., 2005). Very little information related to their experience is available. This gap in knowledge highlights a need for research in this area to better understand children's perspectives. Therefore, our research question was "What are the moral experiences of children living in poverty?"

\section{Methods}

\section{Study design}

Focused ethnography was the methodology chosen for this study. It enabled us to explore children's everyday moral experiences while situating their experiences in their respective sociocultural contexts. In contrast to classical ethnographic studies, it was focused both in scope (by focusing on children's moral experiences in a specific context) and in time (Muecke, 1994).

The study was conducted in a nonprofit community organization offering an academic support program to children living in poverty in Montreal, Quebec, Canada. The organization was funded mainly through private donations and provided services for vulnerable populations. Among these, an academic support program was offered to children ranging in age from 5 to 16 who attended biweekly sessions. Some sessions were dedicated to homework help, while others focused on learning French. The program took place in two different locations: a social housing setting, and a building close to a reception school for new immigrants. Children were recruited mostly through word of mouth, as well as through advertising in both locations. Children attended the program in groups of 10 to 25, with three to four educators present at each session to support children, help them with their homework, or provide additional exercises related to schoolwork or learning French. The educators, who held a professional degree in psychosocial adaptation, were paid by the organization and were assigned to the same group of children throughout the year. The academic support program was selected for this study because it served the population of interest (i.e., children considered as living in poverty). To promote a participatory research approach, staff members from the organization were involved in key stages of project design and implementation through several meetings over the span of a year.

Ethical approval from McGill University's Institutional Review Board and administrative authorization from the partner organization were obtained prior to the start of the study. Data collection and analysis were performed by a graduate nursing student (Olivia Saint- 
Laurent), with support from a doctoral nursing student in childhood ethics (Marjorie Montreuil) and a senior qualitative researcher with a background in childhood ethics (Franco A. Carnevale).

\section{Data collection}

All participants were recruited through the academic support program. A program educator introduced the research project and the researcher to potential participants. Written consent was sought from adult participants and parents of child participants, either through a one-on-one meeting with the researcher or through a consent letter sent home via the children if parents did not come to the academic support program. The consent letter presented the study's purpose as "to gain a better understanding of children's daily experiences of right and wrong, good and bad, and fair and unfair (e.g., helping others, telling the truth, lying, cheating, or bullying"). Activities such as participant observation and one-on-one meetings were described, and the option to withdraw consent at any time was emphasized. Verbal assent was sought from children whose parents consented to their participation in the study. Only child participants for whom both parental consent and child assent had been obtained were enrolled in the study.

Children were recruited using consecutive sampling to examine their moral experiences through participant observation and individual interviews. The main challenge related to the recruitment of children came from the difficulty communicating with parents (e.g., often having to send consent letters home via children rather than meeting parents directly). Consistent with a focused ethnographic framework, participant observation was the primary method for data collection because it has been shown to produce richer data and foster insights more readily than other research methods (such as structured interviews) with children (Carnevale, Macdonald, Bluebond-Langner, \& McKeever, 2008). We conducted 22 sessions of participant observation during the academic support program with groups of 10 to 25 children, over a span of eight weeks. Data generated from participant observation were recorded in field notes and reviewed after each observation session. Numerous informal interviews were conducted with the children during the participant observation sessions. In addition, a participatory activity was designed in consultation with the educators to provide an additional focused forum to foster reflection and stimulate group discussion on different themes, such as stealing, helping, and sharing. The activity consisted of three role-play sketches followed by a debriefing period, and was conducted with children from one of the groups. Children were divided in small groups and asked to role-play in front of the group how they would act in different scenarios (see "Results" for more detail related to the content of the scenarios). Notes from observations during the activity itself, as well as feedback from child participants and educators, were recorded in field notes.

Semistructured individual interviews were also conducted with nine children (aged 5 to 11) to further explore morally relevant subjects that came up during informal interviews or interactions with peers (Fetterman, 2010). Interviews lasted between five and ten minutes, and everyday good and bad experiences were explored in an open-ended manner (e.g., "What do the words good or bad mean to you?"; "Tell me about something good or bad that happened at school today. What seemed good, bad? Who was involved? How did you feel?"). Of the nine children who were recruited for interviews, new immigrant children and children living in social housing were similarly represented (five and four participants, respectively).

Semistructured interviews were conducted with three mothers of children from the program to provide information on the social context in which the child participants lived and inform on the children's experiences. Semistructured interviews were also conducted with three educators from the program to provide additional data related to the children' social context, as well as on institutional structures, practices, and norms in the study setting. Four additional educators participated in informal conversations that occurred during participant observation. Documents provided by the educators pertaining to the academic support program, such as program rules and tools used to monitor academic progress, were used to provide additional contextual data on institutional structures, practices, and norms.

\section{Data analysis}

Line-by-line coding of the raw data was conducted in the original language (French or English). Codes were then arranged into meaningful thematic categories in an iterative process. Each source of data was thus considered as an opportunity to explore ongoing analyses and interpretations of previous data. Once data collection was completed, all data were reanalyzed as an integrated whole. Identified themes were presented to educators from the academic support program, who were invited to provide comments and feedback to help inform the interpretation of results.

Credibility and trustworthiness were enhanced by a variety of strategies. Author Olivia Saint-Laurent kept a field journal to note a daily schedule of activities related to the research project, notes from participant observation, and a personal diary, including a 
reflective commentary of her experience to help her identify potentially problematic preconceptions. Credibility was also enhanced through source triangulation by using data from three different groups of children, as well as from parents and educators.

\section{Results}

Throughout data collection, a key aspect of children's moral experiences was related to what participants considered as social barriers in children's social environments, mainly stigmatization, family isolation, and linguistic barriers for new immigrant children. The linguistic barrier was mentioned numerous times by new immigrant children; however, stigmatization and family isolation were only mentioned explicitly by adult participants, who perceived these challenges as important and central to children's experiences. The academic support program where the study took place was both an environment where adults actively tried to provide a space where children were supported to overcome these challenges as individuals, and a highly structured environment with group rules and academic expectations in place. Children navigated these different challenges, highlighting some of the social barriers they perceived and what they considered important.

Verbatim quotes from interviews and excerpts from field notes are presented to illustrate the identified themes. Brackets are used to make grammatical adjustments to quotes to increase clarity, either removing irrelevant parts of sentences or adding words that were omitted, without changing the sense of the initial statement. We use the word "educator" to refer to staff members of the academic support program, whereas "teacher" refers to the formal school environment.

\section{Various social barriers affect children living in poverty}

We call "social barriers" elements of children's social environments, whether at home, at school, or with peers, which were interpreted as impeding them from expressing their views and actively taking part in social life.

\section{Stigmatization.}

People who access our services come from underprivileged backgrounds, whether it be social housing, or [...] new migrants [...] they are often in precarious situations. [One of their ethical concerns related to] stigmatization [is] the way their families are perceived. [...] Just living in [a social housing setting] is not well perceived [...] many children will say "I am poor." [...] Just being in that environment, they already have that label: poor. (Interview with an educator)

Educators emphasized stigmatization as one of the challenges experienced by children coming to the program. They reported that children shared with them being labelled as poor, which educators considered stigmatizing. They further described two components of poverty: "economic (or situational) poverty" (e.g., a family living on insufficient income), and "social poverty" (e.g., a family living in isolation, with few friends or family members outside of the household). According to the educators, stigmatization came from different sources, such as teachers, peers, neighbours, and parents.

Educators recalled a child from the program who was identified as "a total disaster" by a teacher and for whom extra efforts and support were "not worth it." Some children also disclosed to educators that they were set apart from their peers, "being put in a corner of the classroom" or "being told in front of the whole class that "'they were] going nowhere in life." Educators believed that the stringent socioeconomic climate in Quebec at the time this study was conducted (as evidenced by budget cuts in schools and community services) jeopardized the services offered to children living in poverty, because some teachers were "overwhelmed," "out of breath," and "fed up," and that this might cause children to "fall through the cracks."

\section{Family isolation.}

In Iran, their family was wealthy. They had a big family, a lot of people around, including a lot of cousins and friends of the same age for her son to play with. Here, there is one Iranian child who is the same age as her son. That child has been to their house a few times to play Xbox with her son. (Field notes, interview with a mother)

All parents interviewed reported some level of social isolation, regardless of their cultural background. All parents interviewed were 
currently the only parent living with their children, whether that was temporary (e.g., spouse living abroad awaiting visa) or long term, and had few family friends or family members to help them outside of their household. This was reported to be a heavy burden; some parents reported fatigue and high anxiety levels. One mother, who had arrived in Canada two years earlier, said multiple times: "I worry about [my son] all the time."

Educators reported that some of the parents of children attending the program "felt helpless" and unable to stand up for their children when faced with stigmatization at school, saying "[they were] exhausted" and did not "have the time [or] the energy" to confront teachers. According to educators, this was associated with the fact that these parents also bore stigmatizing characteristics, such as low education levels or a language barrier. Educators believed these circumstances further reinforced the "cycle of poverty" in which children accessing the program were living, as parents were at times unable to fulfill their parenting role and advocate for their children when they encountered injustices at school, whether with peers or with their teachers. According to the educators, this could also have had a negative impact on older siblings in the family, on whom were imparted some of their parents' responsibilities in caring for their younger siblings.

\section{The language barrier for new immigrant children.}

I ask one of the children how things are at school. He says it is hard because "French is hard." I ask if the teacher helps him understand. He says that his first teacher was good because he was from here and French was his first language. Now, he does not like his teacher because the teacher's first language is another language. When some of the child's peers, who also speak that language, do not understand, the[ir] teacher helps them by translating in their mother tongue. The child asks why he could not have a teacher who speaks his mother tongue. (Field notes)

New immigrant children directly referred to the language barrier at school as a significant challenge. As some of the participants had been in Canada for less than a year, it was clear throughout our conversations that not knowing certain words yielded daily challenges. For example, two children who were interviewed did not know what the words "fair" and "unfair" meant, either in English or in French, and had to look up the words in their bilingual dictionary.

One time at school, her son was hurt by another child (she gestures hitting her own throat), but he could not express what had happened to the teachers, because of the language barrier [...] She said: "It is difficult for him to talk, he does not know how to ask and does not want to disturb." (Field notes, interview with a mother)

New immigrant families who did not speak either English or French fluently prior to their arrival in Canada all identified their difficulty to communicate due to the language barrier as their main challenge in overcoming isolation and stigmatization. Additionally, parents reported on occasion that their child had been a victim of bullying at school, and had been incapable of explaining what had happened to the teachers because of the language barrier.

\section{Children are active agents in the context of the academic support program}

The academic support program was a space where the challenges mentioned above were acknowledged and where children were supported and encouraged to learn to navigate those challenges. Within the program itself, children showed their capacity to accommodate and challenge rules, showing nuance in their actions for everyday experiences.

Children navigate the challenges they encounter with help from the academic support program. The barriers identified above highlight some of the specific challenges faced by children living in poverty in the context of this focused ethnography. Children and families who participated in the study presented the academic support program as an environment where, despite the academic focus, children were supported to address the social barriers they encountered in their daily lives.

Our mission, I would say, is really to break the cycle of poverty; well, for the child to succeed in breaking [his or her] own poverty cycle. [...] We think that education is what will allow the child to [break that cycle], [...] by giving [him or her] the right tools; [...] everything we do is through an educative approach. (Interview with an educator) 
The academic support program was both a structured environment, where children had to meet academic objectives, as well as an environment where adults actively tried to provide a space where children were empowered to overcome the social barriers they encountered. Class rules were in place at the academic support program to give structure to the interactions between staff and children (e.g., "During the homework period, I focus on my homework and I whisper"). The rules were on display in one of the two settings, accompanied by pictures to help convey their meaning. Rules were read and explained to both groups at the beginning of the school year, and were reiterated by the educators whenever they were not followed. Educators from the program also gave high importance to establishing and maintaining trusting relationships with the children.

We really believe in [establishing a trusting relationship]; that's the approach we use here. [...] We don't get mad at them for any little thing, we give a lot of chances, we allow them to ... you know, if they're having a bad day, they can express the fact that they're having a bad day; we're not going to say "sit down, be quiet, I don't want to hear it" [...] we try and offer a safe place for the time that they are with us. (Interview with an educator)

Educators considered each child's individual challenges and were flexible when applying the program rules. They sought to achieve academic expectations while working to help create a space where children could express themselves. However, because the primary focus of the program was to provide academic support for children, educators sometimes felt constrained in their opportunities to address social barriers. To palliate for limited time and resources (e.g., one educator helping multiple children with their homework), educators regularly set time aside in the program's schedule to address the challenges children encountered.

[The academic support program] is very good to help with speaking and understanding French. It helps [my son] more than school [...] there is kindness here [...] it helps him adapt. (Interview with a mother)

Parents appreciated the academic support program and valued the relationship they developed with the educators. Children enjoyed coming to the program, as evidenced by their smiles and laughter when they arrived. Children also directly voiced their appreciation, saying they "liked everything from the program" and they appreciated "getting help to do homework [they] didn't understand." Educators reported seeing changes in children who attended the program for a few years. For example, some children who did not ask for help before no longer hesitated to ask questions when they did not understand, and overall academic standings were reported to improve.

Children navigate implicit and explicit program rules. In the structured context of the academic support program, ongoing interactions between adults and children from the program, as well as among children themselves, highlighted children's capacity to navigate implicit and explicit rules. Children navigated these rules, showing nuance in their actions.

For example, during the activity we conducted with one of the groups, children acted and spoke in ways that accommodated implicit rules or norms such as helping, sharing, and being fair. Children were asked what they would do when faced with different situations: In the first scenario, two bystanders witnessed a child whose schoolbag was stolen; in the second scenario, two children witnessed a classmate having trouble doing an exercise because he did not understand what the teacher was asking; in the third scenario, three children were playing together and noticed a child who was alone in the school yard. In the first scenario, children playing the roles of the bystanders decided to pursue the thief and brought the bag back to the "victim." Another child suggested to "tell the teacher" what had happened. One child expressed that it's good to help other children because "if you help now, then later on they can help you." In the second scenario, children found creative ways to explain the exercise to their classmate (e.g., miming, writing numbers on an imaginary piece of paper). In the third scenario, children invited the child playing alone to join them. One child mentioned that this was nice, because he did not have friends. One participant said that he would not have dared to ask the child who was alone to come and play with them, because he was too shy. As exemplified above, this activity contributed to the understanding of children's daily moral experiences and what they consider important and right or wrong to do.

A 7-year-old child told me his friend was "cheating" while doing his homework, copying the answers from a page that he hid from me rather than doing the exercise on his own. When I asked him why he volunteered this information even though he was not involved in the situation-and therefore did not have to fear a negative consequence for himself, the child said: "cheating is bad." I asked him what that meant. He repeated that it was bad. (Field notes)

Children at the academic support program most often acted to accommodate local rules. They also demonstrated self-directed 
assessments of the conduct of others, for example, identifying another child's action (copying answers in his homework) as "bad." On another occasion, a child asked two of his friends to "speak French please," encouraging the other children to comply with a rule of the program. However, children also sometimes challenged or disregarded rules. For example, a group of children playing "human tic-tac-toe" during play time tried to communicate with each other to help their team win the game, although educators had explained that communication among peers was not allowed during the game. Collaborating to win the game became more important than the possibility of losing a point because rules were not followed. Children typically acted in ways to foster friendship relationships with other children in the program, for example, greeting other children they knew by smiling and talking with them before the beginning of each session, while also sharing what they considered as wrong as in the cheating example above.

\section{Discussion}

The social barriers identified formed part of the background context in which children's moral experiences were situated. For instance, within the academic support program, stigmatization was identified by educators and parents as one of the main ethical concerns for the children accessing the program. Child participants did not directly disclose their experience with stigma to us, but educators in the program gave specific examples of encounters with children they interpreted as linked to stigma, for example, recalling times where children were labelled as poor or excluded by their peers or by adults around them. Educators thus perceived stigma related to poverty as a barrier that needed to be addressed in order to help the children, in their best interests. Stigma has been described as "a special relationship between an attribute and stereotype," characterized by the discrepancy between someone's self-perception and the way he or she is perceived by others, and related to shame or discredit (Goffman, 1963). Here, the stigma lived by children was defined in different contexts, such as school and home; it has been previously reported that schools can be a "corrosive and damaging environment" for children living in poverty (Brabant et al., 2016; Ridge, 2011). Educators mentioned helping children navigating the social barriers they encountered in their daily lives by helping them develop their academic capacities. As per the program's educators, this would empower children to break their own cycle of poverty, thereby actively managing their stigmatization. In the study, the opportunities to discuss with children were limited, because the interactions had to occur during the program sessions. In future studies, an exploration of children's own perceptions of stigma would greatly contribute to understanding what it means to them and what they consider helpful and in their best interest. Research on stigma related to physical disability suggests that children with stigmatic qualities seek to actively manage their social exclusion (Carnevale, 2007).

Poverty was defined by the program educators as encompassing economic hardship and social isolation, which is congruent with the broader definition of poverty found in the literature (United Nations Development Programme, 2014). This broader definition helped us identify common challenges shared by children living in economic poverty, as well as challenges specific to immigrant children (e.g., language barriers). It also highlights that social isolation can contribute to poorer health and well-being for these children.

The language barrier was a central preoccupation for new immigrant families. Immigrant children who did not speak either French or English struggled with learning a new language and integrating it in schoolwork, especially when they arrived after the beginning of the school year. Although unsurprising, academic hardship is an alarming reality for immigrant children arriving in Canada; research has shown that they are at higher risk for school dropout (Corak, 2011). Parents also disclosed events in which their children had been bullied at school and could not report it to their teachers because they lacked the words to explain what had happened. Although violence and social exclusion toward immigrant children at school have been reported in the literature (Brabant et al., 2016), we found this result surprising considering that immigrant children from our study attended a reception school in which all students were immigrant newcomers and where there was no dominant local ethnic group.

These children also demonstrated active agential capacities - they were not passively halted by the barriers they encountered. Children modified their actions to adapt to the context of the academic support program, showing that they were attuned to their environment and to the moral implications of their actions and decisions for others. This is congruent with research that shows that young children have the capacity to distinguish moral violations from "conventional violations" (Cushman, 2008), and it suggests that navigating program rules was not done arbitrarily. Our results thus show children's capacity to act as agents mindful of moral values and able to navigate both implicit and explicit rules.

\section{Limitations}

Many methodological challenges arose during data collection, which led to a smaller number of child participants than anticipated. In particular, difficulty communicating with parents to obtain consent limited recruitment. The consent process required the signature 
of highly formal documents that were not familiar to all. Using a verbal consent process for studies such as this one, in which risks for participants are minimal and considered to be no greater than those experienced in the person's everyday life, could facilitate this process. Future studies could look at addressing methodological barriers to have easier access to these children. Notably, a longer presence in the field would allow the researcher to gain better access to the population. We used a participatory research approach, in which educators were involved in key stages of the study design and implementation, but we were unable to similarly integrate children's input.

\section{Implications for Research and Practice}

The group activity was greatly appreciated by both educators and children. Educators expressed their intentions to include similar activities in their program on a regular basis in the future. They reported that the activity had helped them gain insight into children's moral lives. They also appreciated creating a space for children to discuss such matters at the academic support program, thereby furthering the trusting relationship between children and educators. In this sense, this study has generated knowledge that will be useful when exploring the subject of moral experiences in the context of this academic support program.

The knowledge resulting from this study could be used to help sensitize educators and other service providers who work with children in poverty, whether in community organizations or schools, to promote a better understanding of the experiences of these children. Looking at children from different populations is important, for interventions and policies to be optimally attuned to the specific needs of vulnerable children.

\section{Conclusion}

Our results highlighted that children living in poverty face many social barriers. The children who participated in this study navigated these challenges with the help of the academic support program, which offered an environment where children could address some of their concerns, for example, through their relationship with people from the program. By having more information about the moral experiences of children living in poverty, we can help make the best interests principle more child informed by better recognizing children's vulnerabilities as well as their capacities to act as moral agents.

\section{Acknowledgements}

We gratefully acknowledge the valuable contributions of the academic support program staff at the Welcome Hall Mission in Montreal, Quebec, Canada: Sophie Aubras-Gabriel, Thierry Cherilus, Nathaniel Nurse, and Rodelyne Pierre.

\section{Funding}

This work was supported by a Research Development Initiatives Grant from the Social Sciences \& Humanities Research Council of Canada [grant number 239025].

\section{References}

Barrera, M., Prelow, H. M., Dumka, L. E., Gonzales, N. A., Knight, G. P., Michaels, M. L., ... \& Tein, J. (2002). Pathways from family economic conditions to adolescents' distress: Supportive parenting, stressors outside the family, and deviant peers. Journal of Community Psychology, 30(2), 135-152. doi:10.1002/jcop.10000

Brabant, L. H., Lapierre, S., Damant, D., Dubé-Quenum, M., Lessard, G., \& Fournier, C. (2016). Immigrant children: Their experience of violence at school and community in host country. Children \& Society, 30(3), 241-251. doi: 10.1111/chso.12131

Canadian Teachers' Federation. (2009). Supporting education, building Canada: Child poverty and schools. Ottawa, ON: Author.

Carnevale, F. A. (2007). Revisiting Goffman's stigma: The social experience of families with children requiring mechanical ventilation 
at home. Journal of Child Health Care, 11(1), 7-18. doi: 10.1177/1367493507073057

Carnevale, F. A., Campbell, A., Collin-Vézina, D., \& Macdonald, M. E. (2015). Interdisciplinary studies of childhood ethics: Developing a new field of inquiry. Children \& Society, 29(6), 511-523. doi: 10.1111/chso.12063

Carnevale, F. A., Macdonald, M. E., Bluebond-Langner, M., \& McKeever, P. (2008). Using participant observation in pediatric health care settings: Ethical challenges and solutions. Journal of Child Health Care, 12(1),18-32. doi: 10.1177/1367493507085616

Chen, E., Cohen, S., \& Miller, G. E. (2010). How low socioeconomic status affects two-year hormonal trajectories in children. Psychological Science, 21(1), 31-37. doi: 10.1177/0956797609355566

Corak, M. R. (2011). Age at immigration and the education outcomes of children. Ottawa, ON: Statistics Canada.

Crossley, T. F., \& Curtis, L. (2003). Child poverty in Canada. Hamilton, ON: Department of Economics, McMaster University.

Cui, M., Conger, R. D., Bryant, C. M., \& Elder, G. H. (2002). Parental behavior and the quality of adolescent friendships: A socialcontextual perspective. Journal of Marriage and Family, 64(3), 676-689. doi: 10.1111/j.1741-3737.2002.00676.x

Cushman, F. (2008). Crime and punishment: Distinguishing the roles of causal and intentional analyses in moral judgment. Cognition, 108(2), 353-380. doi: 10.1016/j.cognition.2008.03.006

Ecob, R., \& Davey Smith, G. (1999). Income and health: What is the nature of the relationship? Social Science \& Medicine, 48(5), 693-705. doi: 10.1016/S0277-9536(98)00385-2

Ferns, C., Freiler, C., Friendly, M., \& Tougas, J. (2015). Child poverty, 25 years later: We can fix this: 2014 report card on child and family poverty in Canada. Toronto, ON: Family Service Toronto.

Fetterman, D. M. (2010). Ethnography: Step-by-step. Los Angeles, CA: SAGE.

Goffman, E. (1963). Stigma: Notes on the management of spoiled identity. Englewood Cliffs, NJ: Prentice-Hall.

Hunt, M. R., \& Carnevale, F. A. (2011). Moral experience: A framework for bioethics research. Journal of Medical Ethics, 37(11), 658-662. doi: 10.1136/jme.2010.039008

Montreuil, M., \& Carnevale, F. A. (2016). A concept analysis of children's agency within the health literature. Journal of Child Health Care, 20(4), 503-511. doi: 10.1177/1367493515620914

Morrow, V. (2001). Young people's explanations and experiences of social exclusion: Retrieving Bourdieu's concept of social capital. International Journal of Sociology and Social Policy, 21(4), 37-63. doi: 10.1108/01443330110789439

Muecke, M. A. (1994). On the evaluation of ethnographies. In J. M. Morse (Ed.), Critical issues in qualitative research methods (pp. 187-209). Thousand Oaks, CA: SAGE.

Ridge, T. (2011). The everyday costs of poverty in childhood: A review of qualitative research exploring the lives and experiences of low-income children in the UK. Children \& Society, 25(1), 73-84. doi: 10.1111/j.1099-0860.2010.00345.x

Robinson, L. M., McIntyre, L., \& Officer, S. (2005). Welfare babies: Poor children's experiences informing healthy peer relationships in Canada. Health Promotion International, 20(4), 342-350. doi: 10.1093/heapro/dai017

United Nations Development Programme. (2014). Human development report. Retrieved from: http://hdr.undp.org/en/2014-report

Wall, J. (2010). Ethics in light of childhood. Washington, DC: Georgetown University Press. 